\title{
People with enteral tubes and their carers' views of living with a tube and managing associated problems: A qualitative interview study
}

\author{
Sue M. Green RN, MMedSci, PhD ${ }^{1}$ (D) | Kay Townsend RN, BSc, MSc, Lecturer ${ }^{1}$ | \\ Nikki Jarrett RN, BSc PhD, Senior Lecturer ${ }^{2}$ | Catherine Westoby RD, MRes, Dietitian ${ }^{1}$ | \\ Mandy Fader RN PhD, Professor and Head of School ${ }^{1}$
}

\begin{abstract}
${ }^{1}$ School of Health Sciences, University of Southampton, Southampton, UK

${ }^{2}$ School of Health Sciences and Social Work, University of Portsmouth,

Portsmouth, UK

\section{Correspondence}

Sue M. Green, Faculty of Health and Social Sciences, Bournemouth University, Bournemouth BH1 3LH, UK.

Email: sgreen@bournemouth.ac.uk

Funding information

SM Green is funded by a National Institute for Health Research (NIHR) / Health Education England (HEE) Clinical Academic Training (CAT) Clinical Lectureship for this research project. This publication presents independent research funded by the NIHR. The views expressed are those of the authors and not necessarily those of the NHS, the NIHR, HEE or the Department of Health and Social Care.
\end{abstract}

\begin{abstract}
Background: Nutrition by enteral tube is a complex therapy requiring significant management to ensure safe, timely delivery of nutrients and avoidance of complications. In the home setting, people with enteral tubes and their carers are required to self-manage the therapy, including the need to cope with problems that arise. Whilst previous studies have conveyed experiences of people with enteral tubes, few have described views on enteral tube problems.

Aims and objectives: Drawing on the findings of a previously reported study (Journal of Human Nutrition and Dietetics, 2019), this paper aims to describe in-depth the experiences of people with enteral tubes and their carers of living with the tube day to day and managing problems that arise.

Design: A qualitative descriptive design using semi-structured in-depth interviews was employed.

Methods: A purposive sample of 19 people with enteral tubes and 15 carers of people with tubes participated. Interviews were recorded and transcribed. Using a thematic analysis approach, codes were defined and applied; themes developed and refined. Five themes with associated subthemes were generated, of which one, "living with the tube," is reported in-depth. The COREQ checklist was used.

Results: Participants described the tube affecting both physical and psychosocial being and revealed it had resulted in significant changes to their daily living, necessitating adaptation to a new way of life. Participants reported spending much time and effort to manage tube problems, at times without support from healthcare practitioners knowledgeable in tube management. Discomfort associated with the tube was commonly described.

Conclusions: Living with an enteral tube impacts significantly on daily life requiring adaptations to normal routine. People with tubes and their carers use a range of strategies to manage common complications.
\end{abstract}


Relevance to clinical practice: Knowledge and understanding of how people with enteral tubes live with their tube and manage issues as they arise will enable healthcare practitioners to provide better support.

\section{KEYWORDS}

enteral nutrition, gastrostomy, home care services, nutritional support

\section{1 | INTRODUCTION}

The provision of nutrition and fluid via enteral tube (ET) is an essential therapy for people unable to meet their nutritional or hydration needs by oral intake alone. Whilst this has long been a common therapy in hospitals, an increasing number of people receive nutrition and fluid via ET in the home setting (Ojo, 2015). The number of people receiving this therapy is difficult to estimate (Ojo, 2015). In the UK at least 8,904 people received ET feeding in 2015 although this is a considerable underestimate due to limited reporting (BAPEN 2018). Enteral tubes include gastrostomy and jejunostomy tubes (placed radiologically, endoscopically or surgically) and nasoenteric tubes. People who receive nutrition and fluid via ET in the long-term commonly have a gastrostomy tube placed (Gramlich, Hurt, Jin, \& Mundi, 2018). Nasoenteric and jejunostomy tubes may also be inserted for use in the home setting but this is less frequent (Gramlich et al., 2018).

\section{2 | BACKGROUND}

Enteral nutrition by tube is a complex therapy requiring significant management to ensure timely and safe delivery of nutrients and fluid and avoidance of the many complications that can arise. In institutional care settings, healthcare professionals experienced in enteral nutrition by tube manage ET care, therapy and complications. People who are discharged home from hospital following placement of an $\mathrm{ET}$, and their carers, are required to learn to manage their ET, associated therapy and deal with issues as they arise (Boullata et al., 2017; NICE, 2012). Training received can be limited and support following discharge is variable (Green, Townsend, Jarrett and Fader 2019).

There are significant social and psychological implications to living at home with an ET. Nutrition via ET has been described as an appreciable burden of treatment (Jordan, Philpin, Warring, Cheung, \& Williams, 2006). Managing the ET and nutrient delivery is disruptive to lifestyle and time consuming (Bjuresäter, Larsson, \& Athlin, 2015; Mayre-Chilton, Talwar, \& Goff, 2011; Rogers, Thomson, O'Toole, \& Lowe, 2007). The family of the person with an ET are often impacted with some describing the new lifestyle as a struggle (Bjuresäter, Larsson, \& Athlin, 2012; Jukic, Gagliardi, Fagnani, Venturini, \& Orlandoni, 2017). Although the impact of the ET and associated management may be described negatively, the importance of the ET to life is well documented (Jukic et al., 2017; Kwong et al.,

\section{What does this paper contribute to the wider global community?}

- The number of people with enteral tubes living at home is increasing globally.

- People with enteral tubes and their carers are required to manage associated therapy and any issues that arise.

- Community nurses and other healthcare practitioners care for people with enteral tubes and need knowledge and understanding of the experience of living with a tube and managing associated problems to be able to provide appropriate support.

2014; Stavroulakis et al., 2016; Williams, White, Sen, \& Prestwich, 2018). Exploration of people's experience of living with an ET enables healthcare providers to better tailor interventions to meet the needs of people with ETs and their carers.

Dealing with complications is part of ET management. Problems such as dislodgement, blockage, stoma infection and over granulating tissue on the stoma margin are common (Boland et al., 2017; Drake, Ozols, Nadeau, \& Braid-Forbes, 2017; Halliday, Baker, Thomas, \& Bowrey, 2017; Kurien et al., 2012; Rogers et al., 2007; Wei-Kuo, Ning-Chi, Wei-Ming, \& Jeng-Feng, 2014) and can result in hospital admission. Whilst hospital admission may be unavoidable, some visits to the emergency department have been described as potentially avoidable (Correa et al., 2014). Management of complications by healthcare professionals has been described, but there is little documented about how people with an ET and their carers manage ET problems.

The findings presented in this paper are gained from a qualitative study which aimed to explore the experiences of people with ETs and their carers concerning hospital admission for ET-related issues and their views of services that could support management of ETs at home. The primary publication addressing the primary research aim is reported in (Green et al 2019). The study did not aim to explore the full experience of living with a tube but the qualitative approach and the broad interview guide gave participants the flexibility to introduce issues they felt relevant and important. This secondary paper presents one major theme, "Living with a tube," which explores people's experiences of living with an ET and managing associated problems. 


\section{3 | METHODS}

\section{1 | Study design}

A qualitative descriptive design using one to one, in-depth interviews with people with ETs and their carers was used. The methods employed are described fully previously (Green et al 2019).

\section{2 | Participants}

Adults over 18 years living at home with an ET and carers of people with ETs living at home were eligible to participate. Carers who cared for people with ETs of any age were included. Participants were required to have the ability to give informed consent and understand and converse in English language. People with ETs living at home in UK south-central and south-east counties and their carers were sampled purposively according to the above characteristics (Creswell \& Plano Clark, 2018). Purposive sampling was used to identify and select individuals with direct experience of living with an ET at home. The sample size was determined during data collection and analysis. No further interviews were undertaken when it became apparent no new concepts and issues were being raised in interviews. Participant characteristics were collected to enable description of the sample.

\section{3 | Procedure}

Potential participants were approached in a variety of ways:

- via advertisement through a patient group for people with ETs (Patient on Intravenous and Nasogastric Nutrition) and at local events for people with ETs

- through telephone contact by a Research Nurse associated with three GP practices

- through mail contact by their GP practice organised by the local NIHR Clinical Research Network

- verbally via three community dietitians during a planned clinical visit to a person in their caseload

When potential participants contacted the researcher following an approach outlined above, the researcher explained the study in detail, checked eligibility and issued the Participant Information Sheet (PIS). The potential participant was then contacted within a week to check receipt of the PIS and to arrange an interview date if the person agreed to participate. All participants participated in the study following initial contact.

Interviews were conducted by two experienced qualitative researchers (SG and one other) between October 2015-March 2018. Interviews mostly took place in the home of a person with an ET following University lone interviewing guidance. Two people were interviewed separately and alone in a room in a healthcare location with refund of transport costs. Some participants requested the option of being interviewed with a carer when the study commenced which was supported by the Patient and Public Involvement Group for the study.
No repeat interviews were undertaken, and field notes were not made. Both interviewers were registered nurses, and some participants knew one as a nurse in a Home Enteral Nutrition Team. Interviewers introduced themselves as researchers at the start of the interview to try to ensure participants' responses were not influenced by concern about future care.

An interview guide (Welch \& Jirojwong, 2014) outlining six closed questions concerning participant characteristics and six open-ended questions relating to the study aim was used for all participants and interviews recorded digitally (Cresswell, 2013). Participants were informed that at any point, and without giving a reason, the interview could be stopped and consent withdrawn, up to the point of publication of the findings.

Verbatim transcription was undertaken by a professional transcriber as interviews were undertaken and all interviews anonymised. One researcher checked six transcripts with the recording. Transcripts were not returned to the participants for comment to reduce the burden of the study.

\subsection{Data analysis and handling}

Thematic analysis was used to analyse each interview using the software package NVivo 12. The phases of thematic analysis outlined by Braun and Clarke (2006) were used. A general understanding of the content was gained by reading and rereading the transcripts and initial semantic codes given to key attributes by one coder. These were then expanded, revised and refined by grouping and a list of subthemes and themes developed (Cresswell, 2013; Robson, 2002). The subthemes and themes were reviewed to ensure the main concepts relating to the common, and recurring patterns were presented (Braun \& Clarke, 2006). The data for one of the five themes identified are discussed in this paper. Quotations were purposively selected from a wide range of participants, edited to aid clarity if required and used to illustrate the essence of a theme (Whitehead, 2014). Quotes from participants were labelled as $C$ (carer) or $P$ (person with a tube) followed by an individual research number.

Research data were managed according to University policy. Unique anonymised numbers were assigned to each audio recording and associated electronic file. All data were stored on a passwordprotected University system. Signed consent forms and the study file were stored in a locked cabinet in a locked University office.

\section{5 | Credibility}

The research was conducted rigorously in accordance with the protocol to enhance the dependability of the data and analysis and ensure transparency of methods. Audio recording of the interviews and use of an interview guide and professional transcriber ensured the findings were relevant to the research question and represented the participants' views. Three other researchers independently analysed a proportion of the scripts. The codes, subthemes and themes were then discussed and agreed to enhance credibility. Consolidated 
criteria for reporting qualitative research (COREQ) (Tong, Sainsbury, $\&$ Craig, 2007) were used (See Appendix S1), and the method is reported accurately and commonalities with other studies discussed to enable consideration of confirmability and transferability.

\section{6 | Research approvals}

Written, informed consent was obtained from all participants. The study was approved by a Research Ethics Committee (15/LO/1359), a Trust Research Office and NHS Permission/PIC Authorisation granted by the local CRN to undertake the study in the related Primary Care region.

\section{4 | RESULTS}

Thirty-four people participated, of which 19 had an ET and 15 were carers of people with ETs. Mean interview length was 43 SD 16 min (43 SD $17 \mathrm{~min}$ for people with ETs and 42 SD 16 min for carers). Eleven people with ET were interviewed alone, and eight were interviewed in the presence of their carers. Eight carers were interviewed with the person they cared for, four carers were interviewed with another carer (their spouse or partner), and three were interviewed alone.

The age range of carers was 22-77 years (mean 51 SD 16), and the age of the person they cared for ranged from 3-83 years (mean 41 SD 27). The age range of people with ETs was $47-83$ years (mean 64 SD 9). Thirteen carers and 8 people with ETs were female. Length of time with the tube ranged from 2-240 months (mean for carers 76 SD 90 and mean for people with ET 35 SD 53). Carers mostly cared for people with radiologically inserted tubes (gastrostomy tubes placed under radiological guidance; $n=7$ ), although six had a low profile gastrostomys ( $n=6$ ), two had a percutaneous endoscopic gastrostomy and three had tubes with jejunostomy extensions. People with ETs mostly had radiologically inserted tubes $(n=11)$, although three had a percutaneous endoscopic gastrostomy, one had an NG tube and four had tubes with jejunostomy extensions.

All 19 people with ETs reported living in their own homes mostly with family (grandchildren, children or spouses); only four lived alone. Five people with ETs did not undertake any tube management and nine indicated they mainly managed their tube without support from a carer (although four of these had carer support at times). Two people with ETs had support from salaried carers, and eight were supported by a spouse or partner.

All 15 carers except one reported that they undertook daily tube management. One carer reported being a salaried carer and the other 14 unsalaried carers. Five of the carers described themselves as mother, two as father and one as sister to the person they cared for with a tube. Six of the carers described their relationship as wife or partner to the person they cared for with a tube. One carer described herself as being paid to support the person with the tube. Seven carers reported having salaried carers and three carers reported family members supporting them to care for the person with the tube. Five reported that they cared for the person with the tube without support from other carers.

\section{1 | Thematic analysis}

The five themes and associated subthemes derived from analysis of the transcripts are described by Green, Townsend, Jarrett and Fader (2019)

- Living with the tube

- Home better than hospital

- Feelings about the tube

- Help when you need it

- Cost for NHS

The theme "Living with the tube" is explored in this secondary paper. This theme was a dominant and overarching theme for all participants, and describes recurrent experiences of living with the ET day to day, dealing with tube problems and being left to manage issues. The experiences of carers and people with tubes were very similar resulting in the generation of identical themes so the results are presented together.

Three subthemes were clearly seen in the data. The first related to how participants had to change and adjust their daily activities and routine, the second related to how they dealt with problems and the third related subtheme concerned support for routine management of the ET and problems arising (Table 1 shows the associated theme codes and subthemes).

\section{5 | DAY TO DAY ROUTINE}

All participants described significant changes to their activities of daily living, particularly those related to working and recreation, sleeping and eating and drinking. These were affected by the practical aspects of ET management and how these needed to be incorporated into their daily routine, and the influence of the ET on their social circumstances and psychological well being.

\section{1 | Practical aspects of managing the ET every day}

Participants described the ET and associated therapy as requiring significant time to manage and as an inconvenience because of its effect on lifestyle. This seemed a particularly pertinent issue for those who travelled outside the home for work or recreation. Carrying equipment for the intervention required adaptations to activities outside of the home, as exemplified by one participant's explanation:

You go to places, you've got to have that on your back. You put a nice suit on or something to go out somewhere smart and you've got to carry that around. Then what happens, you are out for the day all of a sudden the alarm goes off and it's air locked. I undo it all and flush it through by the side of the road in the car like, you've got to carry a syringe and you've got to carry boiled water with you to flush the PEG out. You have to change it 
TABLE 1 Codes and subthemes relating the theme "Living with the tube"

\begin{tabular}{|c|c|c|}
\hline Similar codes & Subthemes & Theme \\
\hline Practical aspects of managing the tube every day & \multirow[t]{2}{*}{ Day to day routine } & \multirow[t]{9}{*}{ Living with the tube } \\
\hline Psychosocial effects of the tube on daily life & & \\
\hline Discomfort and pain & \multirow[t]{6}{*}{ Managing tube problems } & \\
\hline Tube displacement & & \\
\hline Tube blockage & & \\
\hline Tube equipment and feed & & \\
\hline Stoma site issues & & \\
\hline Problems with NG tubes & & \\
\hline Support to manage the daily routine of the tube and problems that arise & Left to manage & \\
\hline
\end{tabular}

over and I have to take various tablets as well so I have to take it off for taking tablets and put it back on.

Disruption in night-time sleep routine was described by several and attributed to a variety of causes including continuous overnight feeding and the mechanics of the feeding pump. As one participant summarised:

I never sleep for more than about $2 \frac{1}{2}$ hours. I go to bed and I have to get up for a pee because I'm a man of my age. Go to sleep again, wake up to plug this in and then I don't really sleep when I'm feeding, although last night I did but that's rare, very rare.

Daily activities required to deliver nutrition and hydration via ET were described extensively, as illustrated by one carer describing her morning routine concerning the ET and therapy:

When I first get up in the morning I have to take the feed off him, take the pump off and then I have a tray ready every morning and I have his [feed brand] on it. Because when he first gets up I do his blood sugar every morning, and I put water into him, and then after I put the water in, I put his medication, because he takes medication morning and night, and then I do his [feed brand]. He has to have [feed brand] because that's his, kind of helps him with his calories and everything. And then I flush him again because he has to be flushed a lot.

(C012)

A few participants chose to describe positive effects of the tube on day to day life, in terms of reducing the need to undertake meal preparation. As one participant indicated:

You won't have to eat, it's free so you haven't got to go shopping, you haven't got to cook, clean, wash or wipe up. You know what I mean? I have been looking at it like that and people go "you are mad!". I said "beside the fact that I have to look at it like that", I said, "I do find it quite convenient", I do find it convenient because I know how inconvenient it would be if I did have to go shopping and cook.

To summarise, people talked extensively about the management of the ET and associated therapy as part of an established daily routine both within and outside the home.

\section{2 | Psychosocial effects of the tube on daily life}

The psychosocial effects of having an ET focussed on eating and drinking. As could be expected, this seemed to impact those who could eat nothing by mouth the most. One participant described how not being able to eat distressed her and made her feel rejected at family mealtimes:

It is a shock, a real shock. Because obviously when you sit and have dinner together and everything like that, normally as a family you sit and chit and chat, but the first thing the family are saying is 'do you mind if we eat?', and they feel embarrassed to eat and you feel sad you are not eating. So you feel like you are rejected by everybody.

(P018)

Another described limiting social opportunities outside of the home environment because of not being able to eat:

... if you went anywhere it was mobile, you could take the little machine and the feed and do it if you were out. But I obviously don't go out a lot with it in because it's no good going to a restaurant or anything because you can't eat anyway.

The drive to eat and drink appeared to remain strong. One participant recalled a recurrent dream about eating a meal: 
I woke up three mornings on the trot where I was just going to bite into my breakfast and I woke up, and it's like not again, not again.

Some described eating and drinking against healthcare professional advice, despite the risk, to promote quality of life. As one carer said when interviewed with the person she cared for:

They wanted you to go nil by mouth but a compromise was reached whereby he can have stage one thickened fluids, as many sips as he wants through the day and up to five portions of the $125 \mathrm{ml}$ pureed food for quality of life.

For participants that worked or undertook activities outside the home the presence of the ET and the need to incorporate ET therapy in their everyday lives left them feeling isolated and frustrated at times:

I guess I just tend to think that surely I'm not the only person who has got a tube, there must be lots of people. I don't know if it's just because I'm, am I harder work because I'm busy and I'm always rushing around and so I'm more prone to mishaps? I don't know.

(P001)

\section{MANAGING TUBE PROBLEMS}

Many issues (short term, recurring and ongoing) with the ET and associated therapy that required management were described. Participants reported spending significant time and effort addressing a broad range of issues that they considered a problem, using different strategies to deal with them. Very few participants indicated that they had experienced no problems arising from the ET.

\section{1 | Discomfort and pain}

Discomfort and pain as a result of the ET and associated therapy was described frequently. A few participants reported pain at the time of insertion of a radiologically placed tube. For example, one participant described sitting up when the procedure was finished and experiencing great pain:

when he finished I went up, I coughed, no I heaved to be sick. The pain, oh it was like, oh my god. That's the only time I've suffered like real pain.

Discomfort and pain was also described during replacement of a balloon-retained gastrostomy tube, illustrated by the following quote:
And they said 'no it won't hurt it's just a little pull'. ... They done it and it did hurt! ..... I said 'I thought you said it didn't hurt', they said 'oh you'll get used to that'. I thought to myself they all say that, they all say so and so and so and so, but that's the only information they get because none of them has had it.

(P013)

Living with tube, discomfort and pain at home was not uncommonly described. Some experienced periodic discomfort and attributed this to a particular cause, such as cleaning and pulling of the tube. For example one participant stated:

There's very little pain or anything like that, occasionally it's slightly tender but that can be down to being meticulous with, keep cleaning and things like that, so sometimes I think maybe I've cleaned that a little bit too much or too many times today ...

(P018)

And another:

Oh, when somebody catches it or I catch it then I'Il go through the roof. But other than that, I don't even know it's there. I forget it's there.

(P007)

A few participants described experiencing frequent pain and using various approaches to reduce the pain, illustrated by one participant stating:

I've tried paracetamol and all those but they don't even touch it. Even going over a bump outside in my chair, oh gosh, it really hurts.

Discomfort and pain, therefore, appeared to be a commonly described experience requiring adoption of strategies to manage.

\section{2 | Tube displacement}

Tube displacement was revealed as a concern for many with balloon-retained gastrostomy tubes. Several divulged that they worried constantly about the tube falling out, as illustrated by the words of one carer participant:

we do constantly worry about it coming out.

(COO3)

Comments made by healthcare professionals to avoid tube displacement was reported to amplify the concern by one participant: 
Especially when they say "be careful it doesn't fall out!" It's a worry, isn't it? You think if something goes wrong and it falls out.

Participants described extensively occasions when the tube fell out and the efforts that they had to make to have it replaced. The impact the tube loss had on the ability to stay nourished and hydrated was well recognised, as one participant said:

It's quite stressful, quite traumatic because you are thinking, my god what do I do?, and you know, how am I going to survive?

A few participants described either replacing the tube themselves or planning to replace it if the tube fell out in the future. One carer participant described how she replaced a tube that had fallen out at the weekend, but when she sought help to have the tube position checked was advised to attend the emergency room:

The whole thing had come out of his stomach. So, I thought, argh, so I put it back in because I'd already been told, warned, that if it came out it can close up very quickly. So, I put it back in and I phoned the helpline ...but it was a case of if you really want anything done you've got to go to hospital. .... I said to her well he's still having fluids so he'll be alright without his feeds until Monday morning.

\section{3 | Stoma site issues}

Overgranulation tissue around the tube site was reported as a significant problem by over a third of participants, causing pain and bleeding. Most participants described it as an intermittent problem that required prompt management. Various approaches to management were outlined including the application of various dressings, steroid creams, antibiotics containing cream, silver nitrate, barrier cream and eye cream with different degrees of success. One person disclosed that she experienced it persistently and had tried many interventions:

Silver ones, honey dressings, at the moment we're on $x x x$ (dressing) and $x x x$ (tape) over the top but we've tried loads, honestly, too many to mention. It doesn't seem to get anywhere.

Some people attributed the cause of the problem to a particular factor, such as not keeping the stoma site clean, not changing clothes regularly, infection triggered by swimming and a response by the body to the presence of the tube. As one participant explained:

I think there is always minimal infection going on hence the over granulation because the body is trying to think well it's a foreign object.

Stoma site infection was identified as an issue by over half, requiring medical and nursing management using oral antibiotics, topical creams and dressings. This was a recurrent issue for some participants as illustrated by one quote:

so after the tube was put in the first year ... on and off he constantly was having infection around the PEG site and it was gunky. But then after the summer it did settle. And then the next winter once we had a really nasty infection, really bad, but I knew straight away, I just took him to the GP, antibiotics and some cleaning. The community nurse would come and look at it and suggest a couple of medicines to put on it.

(C011)

A few described constant monitoring of the stoma site for signs of infection to ensure prompt treatment. Infection was attributed to a variety of causes including discharge from the stoma, swimming, coughing, vomiting, pulling of the tube and inadequate cleaning illustrated by the quote from one participant:

I've had a couple of infections on the site. That's not been a problem since I started cleaning every day without fail, sometimes twice a day, using wet wipes.

(P006)

Discharge caused by a stoma infection was described as causing embarrassment because of the resulting smell and soiling of clothes. Discharge from the stoma site without mention of associated infection was also commonly expressed. Some voiced their discontent with the discharge, particularly when the management required time and money resource. As one participant said about the leakage from her stoma site:

It is an absolute nuisance, and because I hate keep asking for dressings I have to buy them and they are so expensive.

(P004)

Similarly to infection, discharge was attributed to factors such as coughing, swimming and a poorly fitting button. Participants managed the discharge by cleaning and using dressings, barrier cream or reusable cloth devices designed to absorb discharge. One participant indicated that she was not informed that discharge could be an issue: 
No-one had ever told me that you would ooze. PEG snot we call it, it's just like a runny nose!

Participants spoke frequently about stoma site issues and the activities they undertook to manage them. Many participants described seeking support from healthcare professionals, particularly General Practitioners, in order to help them to manage the tube.

\section{4 | Tube blockage}

Nearly half of all participants described problems with tube blockage, attributing this to a number of factors including medication, collapsed tube walls, reflux, insufficient flushing, feed coagulation, internal wall erosion and knots. If attempts to unblock the tube failed, then help was sought from community nurses or dietitians and if this did not solve the problem hospital attendance was considered, as one participant summarised:

We would have to call the community nurses to come out to try and unblock it, and then they would have to try and unblock it first. And then if that didn't work we'd have to go to hospital.

As with tube displacement, the impact blockage had on the ability to stay nourished and hydrated was well recognised and relief when the blockage was removed clearly evident. As one participant stated:

Yes, there was a blockage in the tube and I just couldn't get it out, and of course I was worried sick because I wouldn't be able to feed him or flush him. So I phoned my dietician at $X X X$ and she was on holiday so they contacted $\mathrm{XXX}$ and she came here immediately and sorted it.

As with tube displacement blockages occurring at the weekend were viewed as particularly problematic. As one participant stated:

if it blocked on a Friday you would know that you wouldn't get nothing, nothing would happen until the following week.

Techniques to unblock the tube were described in detail. Techniques included cutting the tube below the area of collapsed tube, warm flushes, massaging the tube, use of digestive enzymes and changing the tube (either undertaken by carers of trained to do so or healthcare professionals). Unsafe and unconventional techniques were developed by a few participants to unblock their tube. For example one participant stated:
It got blocked up on holiday. I'm in a foreign country. I couldn't unblock it with a syringe. I went and got the maintenance electrician and he gave me some cable and we stripped the plastic off and we put that down and cleared it.

(P003)

And another described:

I adapted one of the big syringes which gave me plenty of vacuum, so I was able to vacuum it and clear the thing and then work out how to get it.

(P016)

\section{5 | Tube equipment and feed}

Most people talked at length about many issues concerning feed and equipment supply and use. Several participants had experienced receiving the wrong equipment from their pharmacy, such as glass vials of water for balloon volume checks of balloon-retained gastrostomy tubes. Some participants outlined that they keep a "stock" of equipment to avoid running out. Syringes used to deliver feeds, flushes and medications were extensively discussed, particularly issues related to their quality and provision. The differences in the standard enteral feeds available in different areas were reported to be frustrating for two participants when they had to move between two areas.

Several participants outlined that the angle of the tube exiting the abdomen could be redesigned to facilitate day to day living. This was described in terms of avoid pulling rather than aesthetics, for example, one participant stated:

But the problem with the tube is it's sticking out of your tummy, it's about 4 inches above my naval, ... and of course the tube is coming straight out and it then dangles which immediately gets caught between belts and everything else.

(P016)

\subsection{Problems with NG tubes}

Whilst only one person had only experience of an NG tube, several had one before placement of a gastrostomy tube. NG tubes were described as being visually obvious with a high risk of displacement. Facial soreness due to the use of tape to secure the tube in place' was also described. One carer explained:

He had an NG tube, before he had the PEG put in ... it made his face extremely sore and although they showed me how to put the tube down it wasn't until I got home and my mum said 'oh I wouldn't be very happy about doing that in case you put it in the wrong 
place' and it terrified the life out of me, so if that kept coming out I wouldn't replace them.

\section{7 | LEFT TO MANAGE}

Participants described managing their ETs and associated problems with support from healthcare practitioners. However, over half the participants related that they felt they were left to deal with issues with little or no support and described not knowing who to contact for help with tube management. Many described the need to have somebody that they could contact who could support them as illustrated by the following statement:

Sometimes it would be nice to know that there was somebody out there that I could just contact ... because you do feel really isolated.

Other described being able to contact an individual for support if required but otherwise felt as though they were left to manage:

No support from community or anywhere I just deal with it myself. If I get a problem I phone xxx, if I don't get a problem I don't phone anybody.

Some participants acknowledged that support to help them to manage was available and that people required different levels of support, as illustrated by the quote:

We were alright but I can understand a lot of people might not manage and would have needed a lot more input than we did. It was there if we wanted it but we didn't need it.

(C013)

\section{8 | DISCUSSION}

Living with an ET at home has a considerable impact on daily life, as reported in the primary publication of this study Green, Townsend, Jarrett, Fader (2019). This secondary publication reveals the significant time and resource (both physical and emotional) required by people with ETs and their carers to manage the tube, associated therapies and problems as they arise. The practical aspects of tube management require changes to daily life and adaptation to a new way of being. An accompanying effect on psychosocial well being was evident. Barriers experienced and limits faced in terms of social life and social eating appeared at times to reduce enjoyment of life and feelings of well being for some participants. Frustration over managing problems and fear or anticipatory anxiety around future potential problems was a further characteristic of living with a tube.

Enteral tubes have been described as a considerable burden in some studies (Bjuresäter et al., 2015; Brotherton \& Abbott, 2009; Brotherton, Abbott, Hurley, \& Aggett, 2007; Martin, Blomberg, \& Lagergren, 2012; Roberge et al., 2000). Whilst the findings support this, the ET tube was also regarded as life supporting and convenient, as well as providing a feeling of relief that food, drink and medication could be administered without anxiety. This finding is consistent with more recent publications (Jukic et al., 2017; Stavroulakis et al., 2016).

Participants in this study described a variety of problems associated with the tube and the strategies that they employed to manage them. Other studies have reported a wide range of complications (Chang et al 2015, Correa et al 2014, Halliday et al 2017, Lim et al 2018, Rogers et al 2007) with blockage and infection being cited as common in adults (Boland et al., 2017). A recent survey of home carers in Singapore reported constipation, abdominal distension and vomiting as common complications (Lim et al., 2018). Carers and people with tubes in this UK study did not frequently describe gastrointestinal complications. As in other studies, over granulating tissue on the stoma margin was described as being particularly problematic (Kurien et al., 2012). There is limited research to support the management of over granulation warranting further investigation (Townley, Wincentak, Krog, Schippke, \& Kingsnorth, 2017).

Complications of balloon-retained gastrostomy tube also included dislodgement, which has been reported in other studies (Boland et al., 2017). Strategies to avoid dislodgement include timely replacement of the tube, securement of the tube to avoid pulling and checking the balloon integrity according to manufacturer's instructions. However, merely telling the person to be careful to avoid dislodgement can cause anxiety if given no further details of how this can be done.

Of particular note were the narratives of discomfort and pain caused by the ET. Healthcare professionals can work with people with ETs and their carers to develop strategies reduce pain experience by the use of analgesia, topical applications and anchoring devices.

\section{9 | LIMITATIONS}

The findings of this study may not be generalizable; however, they do generate insights with relevance to similar settings. The research context has been described to enable others to understand the findings (Holloway \& Wheeler, 2010) and relate them to their practice setting. The self-selected participants may have had different views to those who did not volunteer to participate. One of the researchers was a member of the HEN service which supported some participants which could have influenced what they said and potentially biases the findings. This was addressed by including participants from areas not covered by the service and using independent analysts. 


\section{1 | Transparency declaration}

The lead author affirms that this manuscript is an honest, accurate and transparent account of the study being reported. Standards for Reporting Qualitative Research (O'Brien et al., 2014) and international standards for authors (Wager \& Kleinert, 2011) were used to ensure transparency (see Appendix S1). The lead author affirms that no important aspects of the study have been omitted and any discrepancies from the study as planned have been explained.

\section{0 | CONCLUSION}

This study emphasises the extensive impact the presence of an ET and the associated management has on people's daily lives, necessitating a significant change to normal routine. People with ETs and their carers develop a range of strategies to enable them to manage common complications of ETs. Knowledge and understanding of how people with ET live with their ET and manage issues as they arise should enable primary care practitioners to provide appropriate support for the person with a tube.

\section{1 | RELEVANCE TO CLINICAL PRACTICE}

People with ETs and their carers have to adapt to living at home with an ET and manage problems that arise. Knowledge and understanding of the enormous impact a tube has on daily living and common problems associated with tubes, such as pain and discomfort, can enable community healthcare practitioners to support people to manage at home.

\section{ACKNOWLEDGEMENTS}

We are grateful to the participants and the members of the Public and Patient Involvement Group for their interest and contribution to the study. We acknowledge the support of PINNT in the development of the protocol prior to funding and for support in recruitment for the study and thank Miriam Avery for conducting several interviews and supporting recruitment.

\section{CONFLICT OF INTEREST}

The authors declare that they have no conflicts of interests.

\section{AUTHOR CONTRIBUTION}

SG was responsible for the conceptualisation, funding acquisition, study conduct, analysis and writing. KT, CW and NJ contributed to the analysis and writing (review and editing) and MF contributed to the conceptualisation, funding acquisition and writing (review).

\section{ORCID}

Sue M. Green (iD https://orcid.org/0000-0003-1760-3679

\section{REFERENCES}

Bjuresäter, K., Larsson, M., \& Athlin, E. (2012). Struggling in an inescapable life situation: Being a close relative of a person dependent on home enteral tube feeding. Journal of Clinical Nursing, 21, 1051-1059. https://doi.org/10.1111/j.1365-2702.2010.03596.x

Bjuresäter, K., Larsson, M., \& Athlin, E. (2015). Patients' experiences of home enteral tube feeding (HETF) - A qualitative study. Journal of Research in Nursing, 20, 552-565. https://doi.org/10.1177/17449 87114568655

Boland, K., Maher, N., O'Hanlon, C., O'Sullivan, M., Rice, N., Smyth, M., \& Reynolds, J. V. (2017). Home enteral nutrition recipients: Patient perspectives on training, complications and satisfaction. Frontline Gastroenterology, 8, 79-84. https://doi.org/10.1136/flgas tro-2016-100736

Boullata, J. I., Carrera, A. L., Harvey, L., Escuro, A. A., Hudson, L., Mays, A., ... Guenter, P. (2017). ASPEN Safe practices for enteral nutrition therapy. Journal of Parenteral and Enteral Nutrition, 41, 15-103. https ://doi.org/10.1177/0148607116673053

Braun, V., \& Clarke, V. (2006). Using thematic analysis in psychology. Qualitative Research in Psychology, 3, 77-101. https://doi. org/10.1191/1478088706qp063oa

Brotherton, A., \& Abbott, J. (2009). Clinical decision making and the provision of information in PEG feeding: An exploration of patients and their carers' perceptions. Journal of Human Nutrition and Dietetics, 22, 302-309. https://doi.org/10.1111/j.1365-277X.2009.00966.X

Brotherton, A. M., Abbott, J., Hurley, M. A., \& Aggett, P. J. (2007). Home percutaneous endoscopic gastrostomy feeding: Perceptions of patients, carers, nurses and dietitians. Journal of Advanced Nursing, 59, 388-397. https://doi.org/10.1111/j.1365-2648.2007.04307.x

Chang, S. C., Huang, C. Y., Lin, C. H., Tu, S. L., Chao, M. S., \& Chen, M. H. (2015). The effects of systematic educational interventions about nasogastric tube feeding on caregivers' knowledge and skills and the incidence of feeding complications. Journal of Clinical Nursing, 24, 1567-1575. https://doi.org/10.1111/jocn.12748

Correa, J. A., Fallon, S. C., Murphy, K. M., Victorian, V. A., Bisset, G. S., Vasudevan, S. A., ... Lee, T. C. (2014). Resource utilization after gastrostomy tube placement: Defining areas of improvement for future quality improvement projects. Journal of Pediatric Surgery, 49, 15981601. https://doi.org/10.1016/j.jpedsurg.2014.06.015

Cresswell, J. (2013). Qualitative inquiry and research design (3rd ed.). London, UK: SAGE Publications.

Creswell, J., \& Plano Clark, V. (2018). Designing and conducting mixed methods research. Los Angeles, CA: SAGE.

Drake, R., Ozols, A., Nadeau, W. J., \& Braid-Forbes, M. J. (2017). Hospital inpatient admissions with dehydration and/or malnutrition in medicare beneficiaries receiving enteral nutrition: A cohort study. Journal of Parenteral and Enteral Nutrition, 42, 730-738. https://doi. org/10.1177/0148607117713479

Gramlich, L., Hurt, R. T., Jin, J., \& Mundi, M. S. (2018). Home enteral nutrition: Towards a standard of care. Nutrients, 10, 1020. https://doi. org/10.3390/nu10081020

Green, S. M., Townsend, K., Jarrett, N., \& Fader, M. (2019). The experiences and support needs of people living at home with an enteral tube: a qualitative interview study. Journal of Human Nutrition and Dietetics, https://doi.org/10.1111/jhn.12656

Halliday, V., Baker, M., Thomas, A. L., \& Bowrey, D. (2017). Patient and family caregivers' experiences of living with a jejunostomy feeding tube after surgery for Esophagogastric Cancer. Journal of Parenteral 
and Enteral Nutrition, 41, 837-843. https://doi.org/10.1177/01486 07115604114

Holloway, I., \& Wheeler, S. (2010). Qualitative research in nursing and healthcare. Oxford, UK: Blackwell.

Jordan, S., Philpin, S., Warring, J., Cheung, W. Y., \& Williams, J. (2006). Percutaneous endoscopic gastrostomies: The burden of treatment from a patient perspective. Journal of Advanced Nursing, 56, 270-281. https://doi.org/10.1111/j.1365-2648.2006.04006.x

Jukic, N. P., Gagliardi, C., Fagnani, D., Venturini, C., \& Orlandoni, P. (2017). Home enteral nutrition therapy: Difficulties, satisfactions and support needs of caregivers assisting older patients. Clinical Nutrition, 36, 1062-1067. https://doi.org/10.1016/j.clnu.2016.06.021

Kurien, M., White, S., Simpson, G., Grant, J., Sanders, D. S., \& McAlindon, M. E. (2012). Managing patients with gastrostomy tubes in the community: Can a dedicated enteral feed dietetic service reduce hospital readmissions? European Journal of Clinical Nutrition, 66, 757-760. https://doi.org/10.1038/ejcn.2012.19

Kwong, J. P. Y., Stokes, E. J., Posluns, E. C., Fitch, M. I., McAndrew, A., \& Vandenbussche, K. A. (2014). The experiences of patients with advanced head and neck cancer with a percutaneous endoscopic gastrostomy tube: A qualitative descriptive study. Nutrition in Clinical Practice, 29, 526-533. https://doi.org/10.1177/0884533614532693

Lim, M. L., Yong, B. Y. P., Mar, M. Q. M., Ang, S. Y., Chan, M. M., Lam, M., ... Lopez, V. (2018). Caring for patients on home enteral nutrition: Reported complications by home carers and perspectives of community nurses. Journal of Clinical Nursing, 27, 2825-2835. https://doi. org/10.1111/jocn.14347

Martin, L., Blomberg, J., \& Lagergren, P. (2012). Patients' perspectives of living with a percutaneous endoscopic gastrostomy (PEG). BMC Gastroenterology, 12, 126-133. https://doi. org/10.1186/1471-230X-12-126

Mayre-Chilton, K. M., Talwar, B. P., \& Goff, L. M. (2011). Different experiences and perspectives between head and neck cancer patients and their care-givers on their daily impact of a gastrostomy tube. Journal of Human Nutrition and Dietetics, 24, 449-459. https://doi. org/10.1111/j.1365-277X.2011.01165.x

NICE (2012). Nutrition support in adults. Quality standard [QS24]. Manchester, UK: National Institute for Health and Clinical Excellence.

O'Brien, B. C., Harris, I. B., Beckman, T. J., et al. (2014). Standards for reporting qualitative research: a synthesis of recommendations. Acad Med, 89, 1245-1251.

Ojo, O. (2015). The challenges of home enteral tube feeding: A global perspective. Nutrients, 7, 2524-2538. https://doi.org/10.3390/ nu7042524

Roberge, C., Tran, M., Massoud, C., Poirée, B., Duval, N., Damecour, E., .. Henry-Amar, M. (2000). Quality of life and home enteral tube feeding: A French prospective study in patients with head and neck or oesophageal cancer. British Journal of Cancer, 82, 263-269. https:// doi.org/10.1054/bjoc.1999.0913

Robson, C. (2002). Real world research. Oxford, UK: Blackwell Publishing.

Rogers, S. N., Thomson, R., O'Toole, P., \& Lowe, D. (2007). Patients experience with long-term percutaneous endoscopic gastrostomy feeding following primary surgery for oral and oropharyngeal cancer. Oral Oncology, 43, 499-507. https://doi.org/10.1016/j.oraloncolo gy.2006.05.002
Stavroulakis, T., Baird, W. O., Baxter, S. K., Walsh, T., Shaw, P. J., \& McDermott, C. J. (2016). The impact of gastrostomy in motor neurone disease: Challenges and benefits from a patient and carer perspective. BMJ Supportive and Palliative Care, 6, 52-59. https://doi. org/10.1136/bmjspcare-2013-000609

Tong, A., Sainsbury, P., \& Craig, J. (2007). Consolidated criteria for reporting qualitative research (COREQ): A 32-item checklist for interviews and focus groups. International Journal for Quality in Health Care, 19, 349-357. https://doi.org/10.1093/intqhc/mzm042

Townley, A., Wincentak, J., Krog, K., Schippke, J., \& Kingsnorth, S. (2017). Pediatric gastrostomy stoma complications and treatments: A rapid scoping review. Journal of Clinical Nursing, 27, 1369-1380.

Wager, E.. \& Kleinert S. (2011) Responsible research publication: international standards for authors. A position statement developed at the 2nd World Conference on Research Integrity, Singapore, 22-24 July 2010. In T. Mayer, \& N. Steneck (Eds.), Promoting research integrity in a global environment. Singapore: Imperial College Press/ World Scientific Publishing. Available to download at the COPE (Committee on Publication Ethics) website at http://publicationethics.org/files/ International\%20standards_authors_for\%20website_11_Nov_2011. pdf

Wei-Kuo, C., Ning-Chi, W., Wei-Ming, W., \& Jeng-Feng, C. (2014). Prospective evaluation of peristomal cutaneous changes among patients with long-term percutaneous endoscopic gastrostomy. Advances in Skin and Wound Care, 27, 260-267. https://doi. org/10.1097/01.ASW.0000449854.63913.25

Welch, A., \& Jirojwong, S. (2014). Data collection in qualitative research. In S. Jirojwong, M. Johnson, \& A. Welch (Eds.), Research methods in nursing and midwifery. Melbourne, Australia: Oxford University Press. pp. 121-139.

Whitehead, L. (2014). Qualitative data analysis. In S. Jirojwong, M. Johnson, \& A. Welch (Eds.), Research methods in nursing and midwifery (2nd ed.). Melbourne, Australia: Oxford University Press. pp. 140- 161.

Williams, G. F., White, H., Sen, M., \& Prestwich, R. J. D. (2018). Patients' experience of enteral feeding following (chemo) radiotherapy for head and neck cancer: A qualitative study. Clinical Nutrition, 38(3), 1382-1389.

\section{SUPPORTING INFORMATION}

Additional supporting information may be found online in the Supporting Information section at the end of the article.

How to cite this article: Green SM, Townsend K, Jarrett N, Westoby C, Fader M. People with enteral tubes and their carers' views of living with a tube and managing associated problems: A qualitative interview study. J Clin Nurs. 2019;28:3710-3720. https://doi.org/10.1111/jocn.14972 